\title{
Water Resource Policies in Montana: Interactive Roles for Undergraduates
}

\begin{abstract}
In 2013, the Montana Department of Natural Resources and Conservation (DNRC) launched a two-year project to update the state's water plan. State officials convened basin-specific citizen councils, and they organized forums at which issues of water management could be brought forward by the public. Based on this input, each basin council was charged with developing specific water-policy recommendations in the form of basin water plans that would inform a comprehensive State Water Plan. In the case of the Yellowstone Basin Advisory Council (YBAC), officials at Montana State University Billings negotiated a contract with the naturalresources department allowing a designated team to provide support for the various activities of the YBAC. One stipulation of the contract was that undergraduates could be involved as members of the support team and have access to all meetings held by the YBAC, including deliberative meetings at which policy recommendations were formulated. Seven students were involved at various stages of the two-year process. Three students participated as reliable, dedicated, and indefatigable support-team members; their contributions to the YBAC effort evolved over the course of 18 meetings. Their contributions can be summarized as: (1) community builders; (2) process facilitators; (3) process moderators; (4) "soft" policy critics; and (5) "soft" policy encouragers. This article explores those contributions as elements of policy development and explains the potential for specific learning outcomes.
\end{abstract}

Given the uncertainty of water supplies in the western United States, and given that some of state's basins were operating under "water plans" (policy guidelines) written in the 1970s, the Montana State Legislature called in 2009 for the development of a comprehensive guide for updating the state's water policies-a State Water Plan (Montana State Water Plan 2015).

In keeping with the state's constitution, which explicitly affirms the public's "right to expect ... reasonable opportunity for citizen participation" prior to the finalization of governmental policy decisions (Montana Code Annotated 2014a), the legislature's instructions called on the Montana Department of Natural Resources and Conservation (DNRC) to engage citizen councils that would recommend policy options for existing uses, future needs, and the protection of the state's water resources against losses to other states (Montana Code Annotated 2014b). Under these directives, the department launched a two-year project in 2013 to write a comprehensive State Water Plan. The project would require finesse, particularly given that Montanans are fond of quoting Mark Twain's remark, "Whiskey's for drinkin,' water's for fightin'."

As a first step, department officials set out to convene four different basin-specific citizen councils that would host public forums at which the general public could bring forward water-management concerns specific to their basins. The council members would also receive technical training and instruction relevant to the water resources of their basins, draft policy recommendations in the form of Basin Water Plans, convene a second round of meetings at which the public could comment on each council's recommendations, and advance a final set of recommendations to the natural resources department for use in developing a comprehensive plan for the state. A variety of agency and technical ex-officio advisors-with expertise ranging from water rights, to fish biology, to hydrology, to climate change-were recruited for each council.

One of the most important watersheds in Montana is that of the Yellowstone River. The basin drains approximately 70,000 square miles, nearly half of which are in Montana (Zelt et. al. 1999). The Yellowstone Basin Advisory Council (YBAC) was convened as the basin-specific citizen stakeholder group. It included members from twelve counties, stretching well over 600 miles in distance. The YBAC ultimately met 18 times over 24 months in various locations throughout the basin.

DNRC officials asked Montana State University Billings for organizational and logistical support for the YBAC. A contract was negotiated setting out various activities of the YBAC that would be supported by a designated faculty team. The contract stipulated that all of the proceedings of the YBAC would be audio- and video-recorded for research purposes. Another stipulation allowed undergraduates to be involved as support-team members with access to all meetings held by the YBAC, including the deliberative sessions in which policy recommendations were formulated.

Students majoring in environmental studies were recruited to help with a variety of research and group-support tasks. 


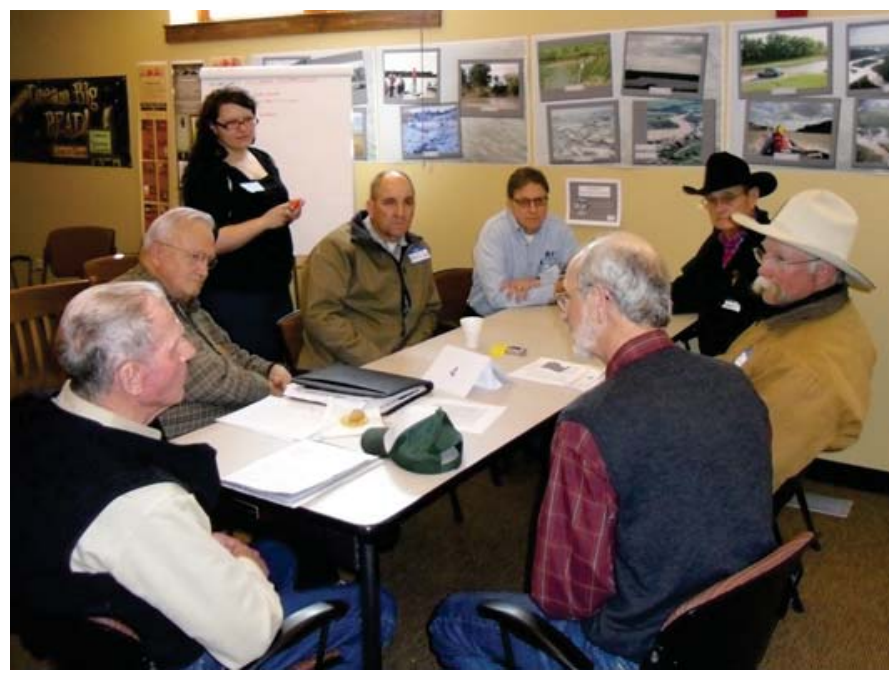

Student Scribe Shanna Lewis records discussion in a breakout group.

They were paid minimally ( $\$ 50$ per day), but their activities would include several learning opportunities:

- Students would observe more than 100 hours of deliberation about water-resource issues and would become familiar with and knowledgeable about the variety and depth of those issues.

- Students would be introduced to a variety of technical resource specialists and would become familiar with the different responsibilities of various agencies, including the differences between the DNRC and the Montana Department of Environmental Quality.

- Students would be introduced to approximately 30 stakeholder representatives and would become familiar with a network of Montanans actively working to meet and to balance the economic and ecological needs of their communities.

During recruitment it was clarified that students' tasks would be wide-ranging, including printing name tags, setting up tables and chairs, making coffee, attending research team meetings, coding data, and writing reports. Seven students were involved at various stages of the two-year process. Their participation ebbed and flowed with course loads, work schedules, and family obligations. Of the seven, three students participated as reliable and dedicated members of the support team.

Importantly, the students' roles evolved over the course of the 18 meetings, and they made subtle but noteworthy contributions to the YBAC's overall mission of providing the DNRC with policy recommendations based on both citizen input and updated scientific and technical information. In retrospect, it is clear to see that the students were operating as: (1) community builders; (2) process facilitators; (3) process moderators; (4) "soft" policy critics; and (5) "soft" policy encouragers.

This article explores the students' contributions and how those contributions met both the initial learning objectives and some important objectives based on literature relevant to stakeholder processes. It also discusses the challenges and successes associated with providing support to citizen councils.

\section{Student Contributions to Policy Development}

The students' efforts had positive impacts in establishing some of the most important group dynamics necessary for the council to carefully deliberate ideas and concerns. Given that water resources and water rights are sensitive topics, the students' impacts were somewhat surprising and especially helpful.

Students as Community Builders. Much of the literature concerning citizen or stakeholder involvement touts the promise of these engagements by noting that they encourage collaboration, cooperation, and consensus across interest groups (Gray 1989; Conca 2006; Jos 2014). At the core of these constructive outcomes is the need for participants to move beyond competitive interests and to allow for a sense of community to emerge (Cooper 2005). The students were instrumental in helping build a sense of community at the YBAC meetings.

For example, the students were assigned the tasks associated with the "welcome table," and it was specifically their job to ensure that each participant was "greeted by name," "signed-in" and "wearing a name tag" at every meeting. YBAC members quickly became comfortable with the ritual of being greeted by our students. The members soon learned the names of the students and were likely to engage them in conversations about their studies and their overall progress in school. YBAC members came to expect students' participation and would ask about a particular student's well-being if the student was absent from a meeting. The students were engaged in the most fundamental element of team building - establishing positive and personally meaningful relationships (Dyer, Dyer, and Dyer 2013).

Students were also asked to make certain the coffee pots were well-stocked during the formal breaks. YBAC participants often thanked the students for doing these support tasks. 
While such tasks may at first glance seem menial, and the "thank you's" may appear to be common courtesies, students were coached to perceive these engagements as networking opportunities.

For the students, the council and the ex-officio members were gatekeepers to communities beyond their immediate access. Whenever formal activities were not underway, students were encouraged to engage the formal participants in conversation. They were building connections that would be useful long after the stakeholder group had completed its tasks. As one council participant told a faculty member, "It's great to meet the next generation of water resource specialists."

In terms of building for the future, the YBAC and the students were beginning to build "strategic alliances," necessary for establishing social capital upon which to draw when future decisions on water resources need to be made in Montana (Inkpen and Tsang 2005; Mintrom and Vergari 1996).

As a further example, the students and the advisory-council members were able to empathize with one another during the extensive technical and scientific training. Against the advice of the research faculty, the agency decided to proceed at a mind-numbing pace: Twenty hours of lecture material were delivered over three consecutive days. It was clear the format did not encourage collaborative or interactive learning; however, students and YBAC members derived a mutual appreciation for one another based on merely surviving the "training."

This appreciation was especially notable during breaks when YBAC members were heard asking the students, "Is this what it's like to be in college these days?' or "Are you getting anything out of all this?" As explained by Dillenbough (1999), the YBAC members and the students discovered a "symmetry of knowledge," especially in terms of the sheer volume of information they were being asked to digest. By the third day-knowing that the students might well be inclined to find reasons to be elsewhere-YBAC members openly marveled at the students' dedication to attending these technical sessions.

Recent studies indicate that maintaining an "agreeableness" among team members is important in avoiding dissatisfaction with ongoing group processes (Kong, Konczak and Bottom 2015). As demonstrated by the examples here, the students were functional community builders who were helping create personal connections and a positive esprit de corps.
Students as Process Facilitators. In spite of their promise as decision-making bodies (Dalton 2008), citizen councils can be unwieldy in terms of power dynamics (McCarthy 2005). It has been noted that when groups convene to deal with natural-resource issues, the members often develop a distrust of the agency with which they are dealing (LaChapelle and McCool 2005). As a result, citizen councils can be especially difficult to keep on-task when the topic is controversial, and counterproductive dynamics can overwhelm the positive potential of a group (Engle 2013). The YBAC experience provided students with opportunities to encourage inclusive interactions that minimized power dynamics. As a result, the students became process facilitators.

Specifically, students were sometimes asked to serve as "scribes" for roundtable and break-out sessions. Moreover, it was their job to facilitate thorough explorations of comments made by participants. They were instructed to record the content of the discussions on large white pads, and they were told to be sure to "satisfy the participants" in recording notes that were clear and complete representations of participants' input. At the same time, the students were instructed to "watch the clock," and they were cautioned that water-resources issues engender "wicked" conversational tangles (McCool and Guthrie 2001).

The faculty provided the students with a discussion protocol, and the students were instructed to use the protocol and "the clock" as mechanisms to guard against wandering deliberations. The students needed to manage inclusive, but focused, discussions. The thoroughness of their note-taking on the large white pads helped balance power and establish trust as participants saw that their input would not be lost or ignored.

As evidenced in the video-recordings of the proceedings, the participants were very respectful of the students' efforts to both keep them on track and to ensure inclusiveness-perhaps more so than when one of the professors tried to get discussion groups back on-topic. At one juncture, a YBAC member responded to a student's suggestion to go back to the original protocol question in this way, "You're right, and we wouldn't want your professor to be mad at you-or us-if we don't get our work done."

These budding coalitions between YBAC members and students functioned to get the work done as YBAC members would willingly "go back to work" as a means of protecting the students and themselves from "bossy" (tongue-in-cheek?) professors. The advisory council members' comments are evidence of "process ownership" (LaChapelle and McCool 


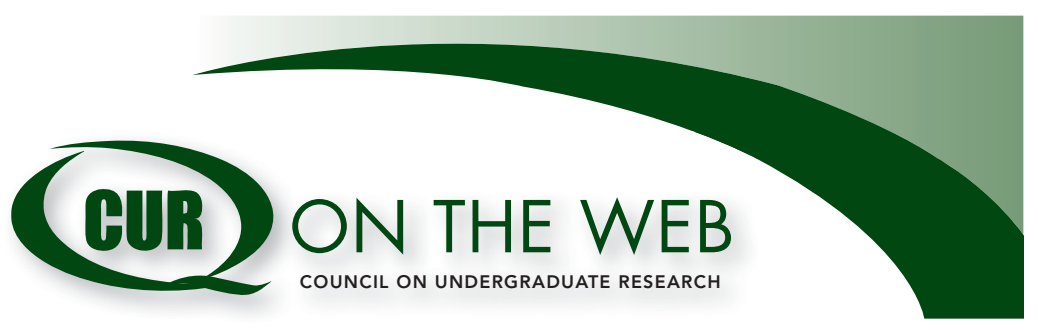

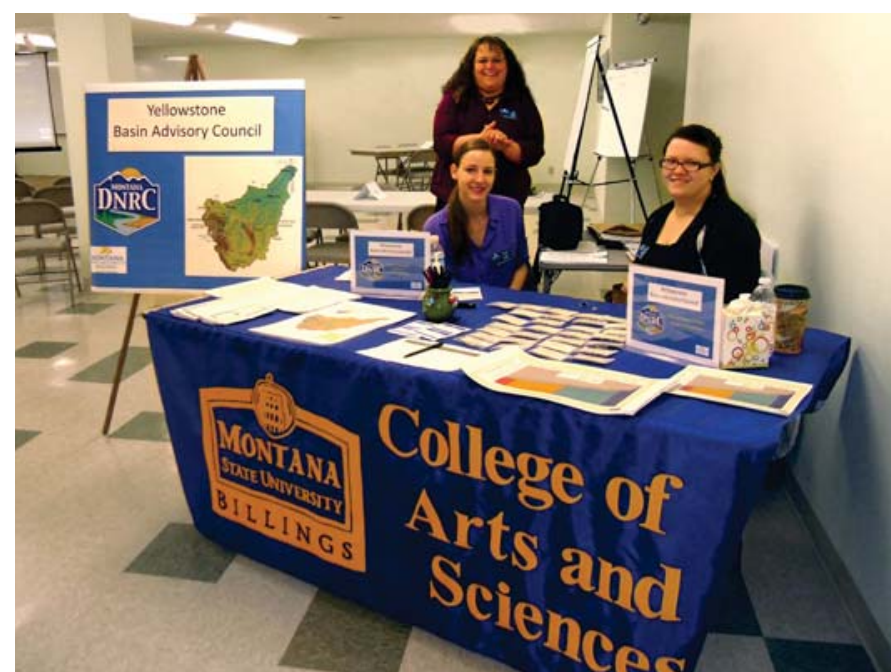

Dedicated "YBAC Roadies" Jodi Kinn (standing), Anne Mary Smith (seated left), and Shanna Lewis (seated right).

2005) as YBAC members recognized their actions would help or hinder the process.

The entire university support team had to "earn" the right to engage in facilitation, and we coached the students to employ various strategies. Weber and Khademian (2008) note that when hired helpers earn such authority, they are indirectly helping to establish trust in the agency sponsoring the proceedings. The students were actively and obviously doing so. The faculty members became very aware of the facilitation successes of the students and determined that, at least at times, it was most effective to have a student perform the facilitation role.

As a bonus, it appeared that consistently having young people in the room-listening, taking notes, and serving as scribes-evoked helpful behaviors on the part of YBAC members. Specifically, the members aided the students' efforts and seemed to purposefully engage in constructive stakeholder behaviors, appearing to recognize they were functioning as role models to young citizens.

Students as Process Moderators. Beyond ensuring inclusiveness, for stakeholder processes to result in sound policy recommendations, the dynamics of the group's discussions must also allow for full consideration of a variety of thoughts and ideas. Organizers of the citizen groups purposely recruited participants with very different perspectives, and this was the case with the YBAC. Unfortunately, some stakeholders bring narrow perspectives to the process, and some are not particularly good at allowing for the fair deliberation of ideas
(Brown 2011; Ghertner 2011). The YBAC meetings provided students with opportunities to actively promote deliberations and interactions that were not constricted in perspective.

For example, during roundtable discussions the students were instructed to be especially aware of how participants who had the advantage of being in the majority were able to "crowd out" minority voices. At breaks, students would report possible problems to faculty members, who could then launch one or more intervening strategies: (a) suggest that the student approach "crowded out" participants during the break and encourage the participants to say more during the next session so that the recorded conversation had a better record of their concerns; and (b) assure the student that once the group reconvened a faculty member would soon "drop in," listen for a bit, and then-if necessary—ask the "crowded out" person for inputs. As process moderators the students not only helped preserve minority ideas, they also helped give deliberative life to those concerns.

As leaders of the support team, the faculty had to be willing to give the nod to the students, especially when the students had earned some respect (or authority) with the YBAC members (Carson, Tesluk and Marrone 2007). At the same time, faculty could not fail to meet the terms of the contract with the natural resources department, nor our responsibilities to our students as learners and novice moderators. Herbst (2010) notes that both civility and rudeness can be seen as strategic choices, yet there is little question that civility in democratic processes is advantageous (Webb 2012). Overall, the students should be given credit for helping to generate "civil discourse" (Leskes 2013); they helped the advisorycouncil members carry out intense deliberation of differing ideas, information, and values, while apparently forestalling and truncating moments of incivility.

Students as "Soft" Policy Critics. Natural resource policies are invariably complicated or as some argue "wicked" (McCool and Guthrie 2001). The intersections of social, economic, and ecological concerns are complex, to say nothing of the troubles introduced when individuals and groups share common resources (Hardin 1968; Berge and van Laerhoven 2011). Moreover, stakeholders do not always have the capacity to help solve problems that have physical, biological, and social dimensions (Hall and Lazarus 2015; Bozeman 2007). The YBAC deliberations provided students with opportunities to move stakeholder groups toward robust decisionsones that would deal with the social and natural system complexities of sharing natural resources.

The students were asked to be aware of how participants' interests might be clouding discussions and/or how the participants might not have enough background in a given subject 
area to move the conversation in a useful direction. Again, at breaks, students would report possible problems to faculty members. Students were then encouraged to help determine which of the attending ex-officio advisors could be helpful to the discussion group. The student would then approach the appropriate advisor about an issue being discussed at her table and actively recruit the technical advisor to the table for input.

Agency personnel also were recruited to discuss policy implications of certain ideas. Bäckstrand (2007) argues that a proper "triangulation" needs to occur among citizen groups, technical experts, and policymakers. Her argument is that none of these groups should operate without sound input from the others. The students were helping construct a working triangulation among the YBAC members, the ex-officio experts, and personnel from the natural resources department.

Also, because the students were residents of the region who anticipated living in Montana for much of their adult lives, they were encouraged to also think as stakeholders with long-term interests in the policy recommendations being made. The students were allowed to use the public comment opportunities, albeit in subtle ways that nonetheless allowed them to become "soft" policy critics. Given that notes and suggestions could be offered anonymously at every meeting, the students were encouraged to fill out comment cards and to discreetly put the cards in the box labelled, "Public Comment Cards Here." In this way, they could comment without compromising their role on the support team, and, once in the box, their comments were inventoried along with all others as formal feedback for the YBAC and the department.The students reported that they commented on various topics, but they were particularly clear that they had asked the YBAC to address the need for accurate measurements of water use at diversion points such as irrigation pumps. While YBAC's attention to written comments was uneven over the two-year period, DNRC personnel were particularly sensitive to such input. Perhaps it was simply due to the permanence of written comments, but agency personnel periodically referred to submitted comments as input the YBAC should not ignore. As a result, the students learned to be "soft" policy critics whose use of "comment cards" positively impacted the substantive content of the recommendations coming from the YBAC.

Students as "Soft" Policy Encouragers. The Corporation for National and Community Service, the federal agency that oversees programs such as Americorp, notes that the attrition rate of volunteers after one year of involvement in a project typically is approximately 33 percent (see Volunteer
Retention 2007). Others note that seasoned participants can strategically wage a "war of attrition," whereby they simply wait for the departure of their opposition from the proceedings (Mullikin and Smith 2003). The students played helpful roles with maintaining active participation by members of the YBAC.

As an example, the students were generally required to attend meetings for full days or even multiple days. When a meeting was held locally, the students were asked to use only class attendance as a reason for their absence. It was common, then, for an individual student to help with set-up at seven o'clock in the morning, to depart for a few of hours to attend classes, and then to return to complete the day's work, including the post-meeting, tear-down at five o'clock.

The YBAC's activities included eight out-of-town meetings. Students were needed at these meetings, too, and they were asked to arrange to be on the road for two to five days at a time. While the university contract covered their expenses, the absences represented hardships in terms of the students' personal and academic responsibilities. Informally, we referred to the three most dedicated of the travelling students as the "YBAC Roadies." It was apparent that the YBAC and the ex-officio members were surprised by, and impressed with, the roadies' attendance. The YBAC experienced only a 5 -percent attrition rate among participants, and there is little doubt that the dedication and hard work of the students helped sustain the overall participation of the members.

The students' efforts can be seen as entrepreneurial in nature (Kim 2010; Roberts and King 1991). That is, their dedication to the opportunity was characteristic of a policy entrepreneur, and that same dedication appeared to stimulate dedication on the part of the YBAC members. The students also learned to accept the ambiguities associated with each meeting's purposes, and they became comfortable with the incremental progress being made at the policy level (Mintrom and Norman 2009). When they returned to a meeting after attending a class and asked for an update on the discussion, they initially seemed perplexed by answers such as, "They have been wordsmithing the same policy section the entire afternoon." However, the students soon became comfortable with the incremental pace of policy development, and their willingness to return to meetings was noted by YBAC members.

Beyond demonstrating their dedication to the project's purposes, and beyond the YBAC members' appreciation for their efforts, the students developed camaraderie with the YBAC members, the ex-officio members, and the DNRC personnel. The last meeting of the YBAC was held in a town over 200 miles from our university, and the ride home with 
the roadies was interesting. While faculty and students were all happy to have the work of the project and the travel demands coming to a close, the students were openly nostalgic about their experiences over the two years of the project. Said one, "I'm really going to miss those guys."

\section{Challenges and Successes}

Citizen groups often convene at the request of state or federal agencies. However, such groups are likely to meet at times and places that make it impossible for a university team to attend. Via our contract, however, the natural resources department gained logistical support, and the research team was assured the meetings had to be at least manageable with our university schedules. Our contract also stipulated that we include undergraduates as assistants whose time and expenses could be minimally compensated. It was difficult to maintain the support team over two years. Both the faculty and the students became fatigued with the project, especially as the demands of each academic term became more intense. From a labor perspective, involving students is not generally the most efficient means for getting work done. Faculty members can more easily complete the tasks themselves as compared to explaining and coordinating the tasks and travel plans.

Yet the involvement of these undergraduates led to exceedingly positive outcomes. In particular, there was ample evidence that the overall learning objectives were accomplished. For instance, when time allowed for simple observation of the YBAC proceedings, the students were asked to fill in conversation data logs that noted: (a) "important comments," which they recorded verbatim when possible; (b) the speaker's name; (c) the date and time; (d) content codes, indicating topical relevance; and (e) process codes, indicating how the comment was either positively or negatively impacting the group's progress. While the students were somewhat mystified by this task during the early meetings, they soon became accomplished recorder/coders. Improvements in their skills and abilities in documenting and coding the proceedings were evidence of growing familiarity with the issues and growing sensitivity to stakeholder processes.

Using the conversation logs and the notes taken during roundtable discussion as data, four of the students prepared research reports. These papers included analyses of the issues being dealt with by the YBAC and the roles that emerged among YBAC members, both positive and dysfunctional. The papers were presented at the 2014 Annual Meeting of the Montana Water Resources Association, where student papers were nestled among papers from research faculty and professional water-resources specialists. To their credit, the students' papers generated questions and active discussions at their sessions. In part due to their dedicated efforts, and in part due to their attendance at the professional meeting, two of the students were recruited into opportunities that began after the YBAC activities ended: One arranged a six-month agency internship, and another was invited to work with a local advocacy group.

Further, by engaging students as support team members for an actual (not experimentally contrived) decision-making group, the students were witnesses to "real-world" dynamics rather than abstract classroom lessons. Consider the value of their first-hand observations of how stakeholders from different geographic regions, with different concerns and perspectives, managed to deliberate important issues. YBAC meetings included a wide variety of participants, including environmental activists and staunch Tea Party representatives.

Due to the diversity of interests, the DNRC hired a professional moderator to run some of the meetings. The moderator introduced "decision rules" designed to achieve consensus, and the students were exposed to the difficulties and stresses of attempting to deliver recommendations in this manner. Of particular interest to the students was the rule that forced participants to accept a recommendation so long as the members could "live with it." Beyond learning about the specific resource issues, students observed conflictmanagement in action. They learned that consensus did not necessarily mean the participants thought the outcomes were perfect or even good, but rather that "livable" recommendations would survive the process. In this way, students were introduced to one of the realities of stakeholder groups: true consensus seldom occurs (Innes 2004).

The efforts of the YBAC and other basin committees were submitted to the DNRC in late 2014. Over the next months, the department condensed the efforts into an overarching State Water Plan that was submitted to the 2015 State Legislature, which approved it with amendments. Unfortunately, as one state official said, the final plan represents "the lowest common denominator" among the recommendations advanced from the various basins. Perhaps this is understandable as state officials knew the plan would generate intense political scrutiny. However, several YBAC members have expressed concerns that the overall plan lacks the richness of the Yellowstone Basin Plan, and preliminary analyses are revealing that the Yellowstone Basin Plan is, in many ways, a superior policy document.

Politics, lessons learned, and overall fatigue aside, the acknowledgments section of the published State Water Plan 
explicitly lists the three most dedicated students by namealbeit mistakenly identifying them as graduate students.

\section{Recommendations}

It is apparent that when faculty members cultivate working relations with agencies, their universities should be willing to engage in contractual arrangements that make it possible for those faculty members and their students to help support state-sponsored citizen councils. Students can fulfill specific learning objectives while gaining real-life experience, and they are afforded numerous opportunities to engage in professional networking opportunities. Most importantly, they can play constructive roles in the dynamics and substance of stakeholder processes.

Such ventures require that all of the commitments are clear. The contracts should: (1) document institutional support, especially so that time away from campus for faculty and students is understood as reasonable and productive; (2) clarify the contractual tasks so that the support team does not become a "catch all" service unit for the agency; (3) recruit more students than will likely be needed, as their time and energies will vary over time; (4) include compensation for clerical and administrative support, especially for managing budgets, travel authorizations, and expense reimbursements; and (5) provide adequate budgets in terms of student stipends, the costs associated with meetings (facilities and refreshments), travel expenses, supplies, and (when possible) teaching load adjustments.

Finally, faculty members should be prepared to undertake a great deal of behind-the-scenes work, especially in terms of orienting students into their roles and helping them cope with the myriad of problems that will arise. In general, it is best when faculty efforts are less, rather than more, obvious. However, while appropriate, faculty members fading from view is not without a certain public pitfall. Imagine my surprise when, at the last meeting of the $\mathrm{YBAC}$, a citizen member approached me, not to thank me, but to comment, "It must have been nice that you could sit in and observe all of our meetings."

\section{References}

Bäckstrand, Karin. 2007. "Civic Science for Sustainability: Reframing the Role of Experts, Policy-Makers and Citizens in Environmental Governance." Global Environmental Politics 50(5): 1217-1234. doi: 10.1162/152638003322757916.

Berge, Erling and Frank van Laerhoven. 2011. "Governing the Commons for Two Decades: A Complex Story" (Editorial). International Journal of the Commons 5(2): 160-187. doi: 10.18352/bmgn-lchr.325.
Bozeman, Barry. 2007. Public Values and Public Interest: Counterbalancing Economic Individualism. Washington, DC: Georgetown University Press.

Brown, Julia. 2011. "Assuming Too Much? Participatory Water Resource Governance in South Africa." The Geographical Journal 177(2): 171-185. doi: 10.1111/j.1475-4959.2010.00378.x.

Carson, Jay B., Paul E. Tesluk and Jennifer A. Marrone. 2007. "Shared Leadership in Teams: An Investigation of Antecedent Conditions and Performance." The Academy of Management Journal 50(5): 1217-1234. doi: 10.2307/20159921.

Cooper, Terry L. 2005. "Civic Engagement in the Twenty-First Century: Toward a Scholarly and Practical Agenda." Public Administration Review 65(5): 534-535. doi: 10.1111/j.1540-6210.2005.00480.x.

Conca, Ken. 2006. Governing Water: Contentious Transnational Politics and Global Institution Building. Cambridge, MA: The MIT Press.

Dalton, Russell J. 2008. "Citizenship Norms and the Expansion of Political Participation." Political Studies 56(1): 76-98. doi: 10.1111/j.14679248.2007.00718.x.

Dillenbourg, Pierre. 1999. "What do You Mean by Collaborative Learning?" In Collaborative-learning: Cognitive and Computational Approaches, edited by Pierre Dillenbourg, 1-19. Oxford: Elsevier.

Dyer, W. Gibb, Jr., Jeffery H. Dyer and William G. Dyer. 2013. Team Building: Proven Strategies for Improving Team Performance, 5th Edition. San Francisco: John Wiley and Sons.

Engle, Nathan L. 2013. "The Role of Drought Preparedness in Building and Mobilizing Adaptive Capacity in States and Their Community Water Systems." Climatic Change 118: 291-306. doi: 10.1007/s10584-012-0657-4.

Ghertner, D. Asher. 2011. "Gentrifying the State, Gentrifying Participation: Elite Governance Programs in Delhi." International Journal of Urban and Regional and Research 35(3): 504-32. doi: 10.1111/j.1468-2427.2011.01043.x.

Gray, Barbara. 1989. Collaborating: Finding Common Ground for Multiparty Problems. San Francisco, CA: Jossey-Bass Publishing.

Hall, Damon M. and Eli Dalton Lazarus. 2015. “Deep Waters: Lessons from Community Meetings about Off-shore Wind Resource Development in the U.S." Marine Policy 57: 9-17. doi: 10.1016/j.marpol.2015.03.004.

Hardin, Garrett. 1968. "The Tragedy of the Commons." Science 162(3859): 1243-1248. doi: 10.1126/science.162.3859.1243.

Herbst, Susan. 2010. Rude Democracy: Civility and Incivility in American Politics. Philadelphia: Temple University Press.

Inkpen, Andrew C. and Eric W. K. Tsang. 2005. "Social Capital, Networks, and Knowledge Transfer." The Academy of Management Review 30(1): 146-16. doi: 10.5465/amr.2005.15281445.

Innes, Judith E. 2004. "Consensus Building: Clarifications for the Critics." Planning Theory 3(1): 5-20. doi: 10.1177/1473095204042315.

Jos, Philip H. 2014. "Advancing Social Equity: Proceduralism in the New Governance." Administration \& Society 46: 1-21. doi: $10.1177 / 0095399714544942$. 
Kim, Younhee. 2010. "Stimulating Entrepreneurial Practices in the Public Sector: The Roles of Organizational Characteristics." Administration \& Society 42(7): 780-814. doi: 10.1177/0095399710377432.

Kong, Dejun T., Lee Konczak and William P. Bottom. 2015. "Team Performance as a Joint Function of Team Member Satisfaction and Agreeableness." Small Group Research 46(2): 160-178. doi: 10.1177/1046496414567684.

LaChapelle, Paul R. and Stephen F. McCool. 2005. "Exploring the Concept of 'Ownership' in Natural Resource Planning." Society and Natural Resources 18:279-285. doi: 10.1080/08941920590908141.

Leskes, Andrea. 2013. "A Plea for Civil Discourse: Needed, the Academy's Leadership." Liberal Education 99(4). Accessed September 25, 2015. https://www. aacu.org/liberaleducation/2013/fall/leskes.

McCarthy, James. 2005. "Commons as Counter-hegemonic Projects." Capitalism, Nature, Socialism 16(1): 9-24. doi: 10.1080/1045575052000335348.

McCool, Stephen F. and Kathleen Guthrie. 2001. "Mapping the Dimensions of Successful Public Participation in Messy Natural Resources Management Situations." Society of Natural Resources 14(4): 309-323. doi: 10.1080/08941920151080255.

Mintrom, Michael and Phillipa Norman. 2009. "Policy Entrepreneurship and Policy Change." Policy Studies Journal 37(4): 649-667. doi: 10.1111/j.15410072.2009.00329.x.

Mintrom, Michael and Sandra Vergari. 1996. "Advocacy Coalitions, Policy Entrepreneurs, and Policy Change." Policy Studies Journal 24(3): 420-434. doi: 10.1111/j.1541-0072.1996.tb01638.x.

Montana Code Annotated. 2014a. Article II -- DECLARATION OF RIGHTS, Section 8. Right of participation. Accessed September 25, 2015. http://leg. mt.gov/bills/mca/CONSTITUTION/II/8.htm.

Montana Code Annotated. 2014b. 85-1-101. Policy considerations. Accessed September 25, 2015. http://leg.mt.gov/bills/mca/85/1/85-1-101.htm.

“Montana State Water Plan: A Watershed Approach, 2015." Montana Department of Natural Resources and Conservation, Helena, MT. Accessed May 28, 2015. http://dnrc.mt.gov/divisions/water/management/docs/state-waterplan/2015_mt_water_plan.pdf.

Mullikin, Thomas Stowe and Nancy S. Smith. 2003. "Community Participation in Environmental Protection." UCLA Journal of Environmental Law and Policy 21(1): 75-95.

Roberts, Nancy C. and Paula King. 1991. "Policy Entrepreneurs: Their Activity Structure and Function in the Policy Process." Journal of Public Administration Research and Theory 1: 147-175.

"Volunteer Retention." 2007. An Issue Brief published by the Corporation for National \& Community Service, Washington, DC. Accessed May 28, 2015. http://www.nationalservice.gov/sites/default/files/documents/via_brief_retention.pdf.

Webb, Derek A. 2012. "The Original Meaning of Civility: Democratic Deliberation at the Philadelphia Constitutional Convention." South Carolina Law Review 64(1). Accessed May 28, 2015. http://papers.ssrn.com/sol3/papers. cfm?abstract_id=217543.
Weber, Edward P. and Anne M. Khademian. 2008. "Wicked Problems, Knowledge Challenges, and Collaborative Capacity Builders in Network Settings." Public Administration Review 68(2): 334-349. doi: 10.1109/ emr.2010.5559144.

Zelt, Ronald, Greg Boughton, Kirk A. Miller, Jon P Mason and Laura M. Gianakos. 1999. "Environmental Setting of the Yellowstone River Basin, Montana, North Dakota, and Wyoming." Water-Resources Investigation Reports 98-4269, Cheyenne: US Dept. of Interior, US Geological Survey. Accessed May 28, 2015. http://pubs.usgs.gov/wri/wri984269/wri984269.pdf.

\section{Susan J. Gilbertz}

Montana State University, sgilbertz@msubillings.edu

Susan J. Gilbertz, associate professor of geography, has been at MSU-Billings for 12 years. She specializes in studying how individuals and communities understand and utilize their natural resources and environs. She is interested in the role of science in policy development, particularly when citizen groups are engaged in policymaking functions.

\section{doi: $10.18833 /$ curq/36/3/10}

